Gender Differences in Social Inclusion of Youth with Autism and Intellectual Disability

Morán, L., Gómez, L. E., Alcedo, M.A., \& Pedrosa, N. (2019). Gender differences in social inclusion of youth with autism and intellectual disability. Journal of Autism and Developmental Disorders, 49, 2980-2989. doi: 10.1007/s10803-019-04030-z

\begin{abstract}
The aim of this study was to delve into the role of gender differences in social inclusion (SI) of children and youth with autism spectrum disorders (ASD) and intellectual disability (ID). A sample of 420 participants with ASD and ID aged between 4 and 21 years old was evaluated using the ASD-KidsLife Scale. Females obtained lower scores in most of the items of social inclusion. These differences remained when the covariables of level of ID, support needs, and age were controlled. None of the items presented differential item functioning as a function of gender. Gender differences that were found in social inclusion are discussed and recommendations are given in order to provide equal opportunities to girls and boys with ASD.
\end{abstract}

Keywords: quality of life; girls; autism spectrum disorder; level of support needs; children; adolescents. 


\section{Gender Differences in Social Inclusion of Youth with Autism and Intellectual Disability}

Traditionally, studies have indicated a higher prevalence of autism spectrum disorders (ASD) in men than in women, with a male-to-female ratio of 4:1 (Fombonne 2003; Gray and Tonge 2005; Honda, Shimizu, and Rutter 2005). Moreover, females with ASD receive (when they do) the diagnosis at a later age than males (Begeer et al. 2013; Giarelli et al. 2010; Lugnegard, Hallerback, and Gillberg 2011; Siklos and Kerns 2007) and their likelihood of meeting diagnostic criteria decreases even when presenting with high levels of ASD traits (Dworzynski, Ronald, Bolton, and Happe 2012; Kreiser and White 2014; Russell, Steer, and Golding 2011). These differences in ASD prevalence by gender might stem from differences in the ASD phenotypes between women and men (Goldman 2013; Kirkovsi, Enticott, and Fitzgerald 2013; Øien et al. 2017), such as more externalizing behavior problems in males with ASD, whereas females show more internalizing symptoms (Kreiser and White 2014; Mandy et al. 2012; Solomon, Miller, Taylor, Hinshaw, and Carter 2012), more coping strategies, and other specific characteristics to compensate for their social deficits (Dean, Harwood, and Kasari 2017; Gould and Ashton-Smith 2011; Lai et al. 2017; Øien et al. 2018). Therefore, there would be many more girls and women on the autism spectrum than previously reported (Attwood 2007; Dworzynski et al. 2012; Loomes, Hull, and Mandy 2017) given that a male bias diagnosis (Russell et al. 2011) that describe well the male phenotype, but misdiagnosed or underdiagnosed females (Attwood 2007; Goldman 2013; Mandy et al. 2012).

Also, intellectual disability (ID) seems to play an important role in ASD gender ratios: male-tofemale ratios decrease to half (2:1) when ASD is diagnosed together with ID (Baird et al. 2006; Fombonne 2005, 2009; Halladay et al. 2015; Hartley and Sikora 2009; Rubenstein, Wiggins, and Lee 2015). Hence, males could be over-represented among those with high levels of functioning and females would be more equally represented among low-functioning cases (Banach et al. 2009). This fact has led to the widespread belief that girls and women who receive an ASD diagnosis present more severe symptoms of ASD and lower intellectual functioning as evidenced by IQ scores (Tsai and Beisler 1983; Tsai, Stewart, and August 1981; Volkmar, Cook, Pomeroy, Realmuto, and Tanguay 1999). However, what may have occurred is that ASD diagnosis has been traditionally restricted to females presenting the classic traits of ASD together with ID and low levels of functioning, whereas the diagnosis is frequently missed for those with high functioning, no impairment or mild impairment of functional language, and no 
other comorbid conditions (Andersson, Gillberg, and Miniscalco 2013; Baird, Douglas, and Murphy 2011; Begeer et al. 2013; Kirkovsi et al. 2013; Rubenstein et al. 2015).

These differences in gender phenotypes may have facilitated females' systematical exclusion from diagnosis and, therefore from research (Sung, Sánchez, Kuo, Wang, and Leahy 2015; Van Wijngaarden-Cremers et al. 2014). Nowadays, gender differences are progressively becoming an important topic for research studies focused on clinical manifestations of ASD (Kirkovsi et al. 2013), but existing research is still scant, present important methodological limitations — such as deficient handling of IQ and age (Kirkovsi et al. 2013; Rivet and Matson 2011; Rubenstein et al. 2015)_, and results are inconsistent (Park et al. 2012; Van Wijngaarden-Cremers et al. 2014). In relation with the deficits in social interaction and communication of ASD diagnostic criteria, some do not report significant gender differences (e.g. Andersson et al. 2013; Mayes and Calhoun 2011; Reinhardt, Wetherby, Schatschneider, and, Lord 2015; Solomon et al. 2012). However, others evidence that males have greater social and communication difficulties (e.g. Backer van Ommeren, Koot, Scheeren, and Begeer 2017; May, Cornish, and Rinehart 2012; Park et al. 2012) while a few defend that females' troubles are more pronounced (e.g. Billstedt, Gillberg, and Gillberg 2007; Hartley and Sikora 2009).

Likewise, knowledge about gender differences in quality of Life (QOL) is extremely scarce especially for children and adolescents with ASD. The few existing studies report no gender differences (Kose et al. 2013; Kuhlthau et al. 2010) in health-related QOL (WHOQOL Group 1998). However, it must be noted that health-related QOL emphasizes physical and emotional wellbeing, so it is considered more limited than the 'individual QOL' construct that is broadly used in the disability field. This 'individual QOL' construct defends a more comprehensive perspective which includes the context and all the important areas of a person's life (Gómez, Verdugo, and Arias 2010; Schalock, Verdugo and Gómez 2011). To our knowledge, based on this socioecological model, only the recent study by Arias et al. (2018) addresses gender differences in QOL-related personal outcomes for youth with ASD. In this research, gender differences were sought on the scores obtained by almost three hundred children and adolescents with ASD and a comorbid diagnosis of ID on eight QOL domains (i.e., material wellbeing, physical wellbeing, emotional wellbeing; interpersonal relationships, social inclusion, rights, personal development, and self-determination). The authors argued that the frequently poor QOL scores obtained by children are not always directly related to ASD but due to other variables such as levels of ID or 
support needs. However, unexpectedly, when controlling these variables, gender differences disappeared in other QOL domains but remained in social inclusion.

Social inclusion was operationalized in the aforementioned research as feeling an integrated member of society, enjoying needed support from others, and participating in normal community activities with other people (Schalock and Verdugo 2002). In this sense, the scientific literature suggests that pupils with ASD experience lower levels of acceptance and peer social support than their reference group (Symes and Humphrey 2010), some of them even suffering social rejection, bullying and cyberbullying (Begara, Gómez and Alcedo 2019). Though, no gender effects have been studied on youth with ASD in any of these indicators of social inclusion, with the only exception to our knowledge of the study by Kuo, Orsmond, Cohn, and Coster (2013), who reported girls' higher rates of participation in social activities in comparison to boys.

In line with the results of Arias et al., the general aim of this study was to delve into the role of gender differences in social inclusion of children and youth with ASD and ID. Complementary analyses are provided at item level in a broader sample of youth with ASD and ID with the ultimate goal of determining if gender adaptations are needed in individualized supports, professional practices, and organizational services aimed at enhancing QOL-related personal outcomes. Therefore, upon the basis of Arias et al.'s results, we hypothesize that:

(a) Females will show lower personal outcomes not only in the total score of social inclusion in comparison to males, but also in every item forming this QOL domain;

(b) Differences will remain even when the effect of ID, support needs, and age is controlled; and

(c) Differences will be due to gender, and not to differential item functioning (DIF); in other words, gender differences will not be due to biased items against females.

\section{Method}

\section{Participants}

The sample was composed of 420 participants. The inclusion criteria were: (a) having ASD and ID; (b) aged between 4 and 21 years old, and (c) attending any educative, social, or health service in Spain. Ages varied between 4 and $21(M=11.97 ; S D=4.73)$. Most of the participants $(79.3 \%)$ were males.

Regarding the level of ID, most had intermediate levels (moderate $=31.7 \%$; severe $=44.3 \%$ ), while the lower (profound $=6 \%$ ) and higher (mild=12.6\%) levels were less represented according to the official records for service providers in which having an official diagnosis of ASD or ID is a mandatory requisite 
to receive supports. The distribution of the sample by levels of support needs was estimated as extensive $(44.5 \%)$ or generalized (36.9\%) in most of the cases, and intermittent $(13.3 \%)$ and limited $(5.3 \%)$ for the rest. Several participants also had other associated conditions, among them: behavioral disorders (16.2\%), physical disability (8.3\%), epilepsy (6.9\%), mental disorders $(6.7 \%)$, visual disability $(3.3 \%)$, and Down syndrome $(3.3 \%)$. The majority attended special education centers $(65.2 \%)$, followed by ordinary education schools (22.2\%), and combined education (12.6\%). Further information about demographic characteristics of participants by gender (male and female) is given in Table 1.

Table 1. Sociodemographic characteristics by gender

\begin{tabular}{llcc}
\hline & & Male $(n=333)$ & Female $(n=87)$ \\
\hline Age & Mean & 11.6 & 13.3 \\
& Median & 12 & 13 \\
Level of ID & SD & 4.7 & 4.5 \\
& Moderate & $15.6 \%$ & $1.1 \%$ \\
& Severe & $36.1 \%$ & $41.4 \%$ \\
Support levels & Profound & $42.9 \%$ & $49.4 \%$ \\
& Limited & $5.4 \%$ & $8.1 \%$ \\
& Intermittent & $5.7 \%$ & $3.5 \%$ \\
& Extensive & $14.2 \%$ & $10.3 \%$ \\
& Generalized & $45.6 \%$ & $40.2 \%$ \\
& Ordinary & $34.5 \%$ & $46 \%$ \\
& Combined & $24.3 \%$ & $13.8 \%$ \\
& Special & $13.5 \%$ & $9.2 \%$ \\
& & $62.2 \%$ & $77 \%$ \\
\hline
\end{tabular}

$I D$, level of intellectual disability

The scales were completed by 237 proxies from 78 organizations in Spain. More than half were professionals (51.5\%), mainly teachers and psychologists. The rest were parents $(48.5 \%)$, mostly mothers (76.5\%). The number of female informants (82.4\%) was much higher than the number of males $(17.6 \%)$. The average time that they had known the people evaluated was 5 years and 4 months $(S D=4.88$ years). Their frequency of contact in $83.6 \%$ of the cases was between two and seven times per week. Participant organizations offered educational services $(74.5 \%)$, social $(23.1 \%)$, and health services $(2.6 \%)$. 


\section{Instrument}

The Spanish version of the ASD-KidsLife Scale (Gómez, Morán, Alcedo, Verdugo et al. 2018) was used. This instrument assesses QOL-related personal outcomes of children and youth with ASD and ID, aged 4 to 21 years old who are users of educational, social, or health services. The scale comprises 96 items organized around the eight domains proposed by Schalock and Verdugo (2002): emotional wellbeing, material wellbeing, physical wellbeing, personal development, rights, self-determination, interpersonal relationships, and social inclusion. The questionnaire is completed by observers who know the person well (for at least six months) and who have opportunities to observe the person for long periods in different contexts (e.g. parents, siblings, guardians, teachers, direct care staff, psychologists, occupational therapists, or any other professionals who provide support to the person). Reliability (Morán, Gómez, and Alcedo in press) and validity evidences based on the internal structure of the scale were proportionated through confirmatory factor analysis, the intercorrelated eight-domain model being the one with the best fit to the data (Gómez, Morán, Alcedo, Arias, and Verdugo 2018). More specifically, in this study, we focused on the social inclusion subscale, which includes 12 third-person formulated items to be answered with four frequency options (i.e. never, sometimes, often, always). The content and formulation of these items can be seen in Table 2. The ordinal alpha coefficient for social inclusion was .90 .

The ASD-KidsLife Scale also includes an informed consent form to be completed by the legal guardians and an ad-hoc survey which was used to collect sociodemographic data about the person being evaluated, the informant, and the service/support provider. The Spanish version of the ASD-KidsLife Scale is freely available on the INICO website (http://sid.usal.es/libros/discapacidad/27385/8-1/escalakidslife-tea-evaluacion-de-la-calidad-de-vida-de-ninos-y-adolescentes-con-trastorno-del-espectro-delautismo-y-discapacidad-intelectual.aspx). An English version of the instrument is available by request (see corresponding author's e-mail) and a Dutch version will also be available soon.

\section{Procedure}

Objectives of the study were disseminated at scientific conferences, on courses, and in social media (e.g. ResearchGate, Facebook, Twitter) and websites of the Institute on Community Integration (INICO, University of Salamanca) and Plena Inclusion (Full Inclusion), the confederation which represents people with ID and their families in Spain and includes 891 organizations. In addition, a web 
search for schools and organizations providing services to people with ID and ASD in all the Spanish regions was conducted and mass emails explaining the study and requesting participation were sent. Those that did not have an email address available were contacted by phone.

The centers that expressed an interest in participating in the study were asked to complete an online survey with their contact details and the person who would be responsible for coordinating the study in each center. Once they had completed the survey, more information about the project and all the necessary materials was provided: a link to access to the electronic version of the scale and to download the printable version, the instruction manual, the informed consent form to be completed for parents or legal guardians of each participant, and the contact details of the research team (i.e. e-mail and phone number) to ask questions and arrange meetings if needed.

Ethical approval for this study was conducted by the University of Oviedo Ethics Committee. All participants were identified by a code to safeguard their identity and ensure the confidentiality of the data that allowed reporting QOL-related outcomes to each center.

\section{Data analyses}

Data analyses were focused on social inclusion scores. Firstly, the fit of the data to the normal distribution was tested using the Shapiro-Wilk test. Owing to the violation of the assumption of normality, the study of differences of means was performed using the Mann-Whitney U statistic (CL=95\%). Effect size was estimated using Cliff's delta (Cliff 1993).

Afterwards, a one-way between-groups analysis of covariance was conducted to analyze the effect of potential explicative variables, such as level of ID, level of support needs and age on social inclusion. Therefore, whereas the independent variables were level of ID, level of support needs and age, the dependent variable consisted of scores on the social inclusion domain. Effect size was estimated via partial eta-squared (Trigo and Martínez 2016).

Once covariance effects were checked, a Moses Test of Extreme Reactions was carried out to check if the experimental variable affected some participants in one direction and other participants in the opposite direction (Moses 1952). Based on the previous result, Differential Item Functioning (DIF) of social inclusion items according to gender was assessed by means of the logistic regression procedure (Hidalgo, Gómez, and Padilla 2005; Zumbo 1999). The logistic regression DIF test was selected because of being a model-based approach, which can be used to detect not only uniform DIF but also nonuniform DIF, and the unidimensionality of the scale assessed, matching participants in the reference and focal groups based 
on total scores. As is known, DIF occurs when people of two different groups show differing probabilities of success on (or endorsing) the item after matching on the underlying trait that the item is intended to measure (Gómez, Hidalgo, and Zumbo 2013). In other words, DIF analyses allow checking if there is a difference in item difficulty for males and females with the same level of ability (i.e. if they are gender biased). The logistic regression method was performed adjusting three models at different stages (Hidalgo et al. 2005). In the first stage, the individual total scores on social inclusion (so conditioning the response on a sum score of the scale) are introduced into the equation, thus adjusting Model 1 (M1) according to the absence of DIF. In the second stage, the group variable (i.e. gender) is added (Model 2, M2). If the explanation of this model with respect to M1 were statistically significant $(p<.01)$, it would indicate a uniform DIF, occurring when the probability of endorsing a certain item is uniformly greater for one of the groups throughout the range of possible scores. In stage 3, the interaction between the group and the total score is introduced (Model 3, M3). If the explanation added by this model with respect to the others were significant, there would be a non-uniform DIF, meaning that the difference in the probability of endorsing an item is not the same for all trait levels (Hidalgo et al. 2005). As any of the items involved in the current study were flagged as showing potential DIF, no matching criterion purification has been considered.

\section{Results}

\section{Gender differences}

Statistically significant differences were found in social inclusion $(p=.002)$, showing a small effect size $\left(\eta^{2}=0.026\right)$, estimated via partial eta-squared (Cohen 1988). Regarding the trends of both sexes, men tended to show larger scores on social inclusion.

When analyzing these differences at an item-level (Figure 1 and Table 2), statistically significant higher scores are also obtained by males in almost all the items. The only exception to this trend is the item that reads 'Specific measures are taken to strengthen his/her participation in the community' (i09), in which women show higher scores than men, although differences are not statistically significant. More specifically, higher scores for males are found in eleven of the twelve items forming the social inclusion domain. Differences were found significant for nine of them, although effect sizes can be considered as negligible $(\delta<0.25)$ in all cases, except for the item that reads 'He/she enjoys holidays in inclusive environments' (i01), where effect size can be defined as small. 


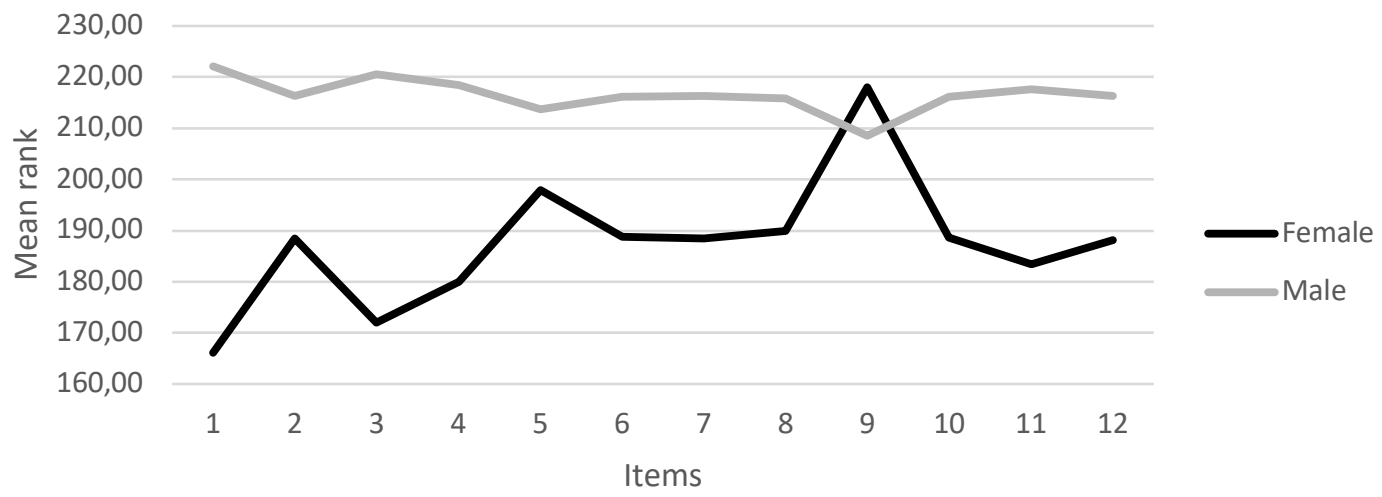

Figure 1. Differences on mean ranks obtained by males and females

Table 2. Gender differences based on Mann-Whitney test

\begin{tabular}{|c|c|c|c|c|}
\hline Item & $\begin{array}{l}\text { Mann-Whitney } \\
\text { U statistic }\end{array}$ & $\mathrm{Z}$ & $p$ & $\delta$ \\
\hline i01 He/she enjoys holidays in inclusive environments. & 10623.00 & -4.034 & $<.001$ & 0.267 \\
\hline $\mathrm{i} 02 \mathrm{He} /$ she is integrated with his/her class peers. & 12565.50 & -2.005 & .045 & 0.133 \\
\hline $\begin{array}{l}\text { i03 He/she carries out leisure activities with same age } \\
\text { peers. }\end{array}$ & 11134.00 & -3.495 & $<.001$ & 0.231 \\
\hline $\begin{array}{l}\text { i04 He/she has opportunities to go to other environments, } \\
\text { different from the place where he/she lives. }\end{array}$ & 11831.00 & -2.817 & .005 & 0.183 \\
\hline $\begin{array}{l}\text { i05 He/she participates in activities in his/her community } \\
\text { with persons outside his/her support group. }\end{array}$ & 13390.00 & -1.153 & .249 & 0.076 \\
\hline $\begin{array}{l}\text { i06 He/she participates in inclusive activities that are } \\
\text { commensurate with his/her physical and cognitive } \\
\text { abilities. }\end{array}$ & 12592.00 & -1.990 & .047 & 0.131 \\
\hline $\begin{array}{l}\text { i07 He/she participates in inclusive activities that are in } \\
\text { line with his/her interests. }\end{array}$ & 12561.50 & -2.056 & .040 & 0.133 \\
\hline $\begin{array}{l}\text { i08 He/she participates in social activities outside the } \\
\text { place where he she/receives services or supports. }\end{array}$ & 12692.50 & -1.884 & .060 & 0.124 \\
\hline $\begin{array}{l}\text { i09 Specific measures are taken to strengthen his/her } \\
\text { participation in the community. }\end{array}$ & 13831.50 & -0.686 & .492 & 0.045 \\
\hline $\begin{array}{l}\text { i10 Persons outside his/her support group interact with } \\
\text { him/her. }\end{array}$ & 12579.50 & -2.003 & .045 & 0.132 \\
\hline $\begin{array}{l}\text { i1 } 1 \mathrm{He} / \text { she participates in leisure and cultural activities in } \\
\text { community environments. }\end{array}$ & 12134.00 & -2.498 & .012 & 0.162 \\
\hline $\begin{array}{l}\text { i1 } 2 \mathrm{He} / \text { she participates in natural groups from his/her } \\
\text { community. }\end{array}$ & 12534.00 & -2.169 & .030 & 0.135 \\
\hline
\end{tabular}




\section{Gender differences controlling the effect of other variables}

Once statistically significant differences were found not only in social inclusion but also in most of the items forming the domain, an analysis of covariance (ANCOVA) was applied controlling the effect of level of ID, level of support needs, and age. After controlling for covariates' scores, statistically significant differences remained between males and females on social inclusion $[F(1,419)=5.11, p=.024]$. Nonetheless, a small effect size was shown $\left(\eta^{2}=.012\right]$. Although differences remain, there is a significant relationship between gender, level of support needs, and age. These variables explain, respectively, 32\% and $28 \%$ of the total variance when analyzing gender differences (Table 3 ).

Table 3. Covariance analysis of social inclusion domain

\begin{tabular}{lcccc}
\hline Variable & df & F & Sig. & Partial Eta squared \\
\hline Gender & 1 & 6.853 & .009 & .016 \\
Support & 1 & 10.996 & .001 & .026 \\
needs & & & .002 & .022 \\
ID level & 1 & 9,507 & .002 \\
\hline Error & 416 & & &
\end{tabular}

\section{Differential Item Functioning on Social Inclusion}

Regarding the Moses Test of Extreme Reactions, it seems that social inclusion differentially affects men and women $(p=.033)$, so rejecting the null hypothesis means that extreme values are not equally likely to occur in both groups. Based on this result, it is likely that none of the items exhibits DIF. To check this hypothesis, items in social inclusion were analyzed to detect DIF as a function of gender. All the items showed negligible DIF (i.e. $\chi^{2}$ test is not significant at .001 level or $\Delta R^{2}<.035$ ) as a function of gender (Table 4), although it is important to bear in mind that, due to the limited sample size assessed, statistical power is less than desirable $(1-\beta=.64)$. 
Table 4. DIF and effect size of social inclusion items

\begin{tabular}{|c|c|c|c|c|c|}
\hline Item & & $\begin{array}{l}\chi^{2} \mathrm{M} 3-\mathrm{M} 1 \\
(p)\end{array}$ & $\begin{array}{c}\mathrm{R}^{2} \mathrm{M} 3- \\
\mathrm{M} 1\end{array}$ & $\begin{array}{c}\mathrm{R}^{2} \mathrm{M} 2- \\
\mathrm{M} 1\end{array}$ & $\begin{array}{l}\mathrm{R}^{2} \mathrm{M} 3- \\
\mathrm{M} 2\end{array}$ \\
\hline i01 & $\mathrm{He} /$ she enjoys holidays in inclusive environments. & $\begin{array}{l}7.206 \\
(.027)\end{array}$ & 0.016 & 0.012 & 0.004 \\
\hline $\mathrm{i} 02$ & $\mathrm{He} / \mathrm{she}$ is integrated with his/her class peers. & $\begin{array}{l}0.546 \\
(.761)\end{array}$ & 0.001 & 0.001 & 0.001 \\
\hline i03 & $\begin{array}{l}\mathrm{He} / \text { she carries out leisure activities with same age } \\
\text { peers. }\end{array}$ & $\begin{array}{l}3.364 \\
(.186)\end{array}$ & 0.003 & 0.003 & $<0.001$ \\
\hline i04 & $\begin{array}{l}\text { He/she has opportunities to go to other } \\
\text { environments, different from the place where he/she } \\
\text { lives. }\end{array}$ & $\begin{array}{l}1.531 \\
(.465)\end{array}$ & $<0.001$ & $<0.001$ & $<0.001$ \\
\hline i05 & $\begin{array}{l}\text { He/she participates in activities in his/her } \\
\text { community with persons outside his/her support } \\
\text { group. }\end{array}$ & $\begin{array}{l}2.899 \\
(.235)\end{array}$ & 0.003 & 0.002 & 0.001 \\
\hline i06 & $\begin{array}{l}\text { He/she participates in inclusive activities that are } \\
\text { commensurate with his/her physical and cognitive } \\
\text { abilities. }\end{array}$ & $\begin{array}{l}0.867 \\
(.648)\end{array}$ & $<0.001$ & $<0.001$ & $<0.001$ \\
\hline i07 & $\begin{array}{l}\text { He/she participates in inclusive activities that are in } \\
\text { line with his/her interests. }\end{array}$ & $\begin{array}{l}0.241 \\
(.886)\end{array}$ & $<0.001$ & $<0.001$ & $<0.001$ \\
\hline $\mathrm{i} 08$ & $\begin{array}{l}\text { He/she participates in social activities outside the } \\
\text { place where he she/receives services or supports. }\end{array}$ & $\begin{array}{l}2,852 \\
(.240)\end{array}$ & 0.004 & 0.002 & 0.002 \\
\hline i09 & $\begin{array}{l}\text { Specific measures are taken to strengthen his/her } \\
\text { participation in the community. }\end{array}$ & $\begin{array}{l}11,725 \\
(.003)\end{array}$ & 0.020 & 0.011 & 0.009 \\
\hline i10 & $\begin{array}{l}\text { Persons outside his/her support group interact with } \\
\mathrm{him} / \mathrm{her} \text {. }\end{array}$ & $\begin{array}{l}1.450 \\
(.484)\end{array}$ & 0.001 & $<0.001$ & $<0.001$ \\
\hline i11 & $\begin{array}{l}\mathrm{He} / \text { she participates in leisure and cultural activities } \\
\text { in community environments. }\end{array}$ & $\begin{array}{l}3.767 \\
(.152)\end{array}$ & 0.007 & $<0.001$ & $<0.001$ \\
\hline i12 & $\begin{array}{l}\text { He/she participates in natural groups from his/her } \\
\text { community. }\end{array}$ & $\begin{array}{l}0.291 \\
(.865)\end{array}$ & $<0.001$ & $<0.001$ & $<0.001$ \\
\hline
\end{tabular}

\section{Discussion}

This study contributes to the evidence obtained to date by using a new instrument specifically adapted to children and youth with ASD, emphasizing a more holistic perspective of QOL, and providing data referring to in-depth analysis at items-level. It also highlights the need to make gender adaptations in supports, interventions, and services aimed at improving their social inclusion.

With respect to the first hypothesis, our results are in consonance with prior results by Arias et al. (2018) but contrary to those centered on the health-related QOL of children and adolescents with ASD that did not find gender differences (Kose et al. 2013; Kuhlthau et al. 2010). In the present study, boys obtained higher scores in social inclusion in comparison to girls. Different types of socialization and roles by gender (Reinhardt et al. 2015) might be part of the explanation for these differences. Thus, for example, boys are usually prone to participate more in shared activities (e.g. hobbies, games, sports) related with their areas 
of interests that imply less social communication (Sedgewick, Hill, Yates, Pickering, and Pellicano 2016; Shields, Synnot, and Kearns 2015). Girls' socialization, instead, is characterized by having conversations with friends (Kuo et al. 2013; Vine Foggo, and Webster 2017), so that females with ASD would confront distinct social demands, challenges, and difficulties (Sedgewick et al. 2016), which in turn would result in exhaustion (Hull et al. 2017; Lai et al. 2017), fostering internalizing disorders (Kreiser and White 2014), and restricting their social participation.

Gender differences in favor of males were not only found in social inclusion but also in most of the items making up this domain, with only one exception: 'specific measures are taken to strengthen his/her participation in the community,' in which girls scored higher but not significantly. In order to find explanations to understand why differences are not significant, it must be noted that this is the only item that is formulated in the passive voice and one of the only two items (the other one is "persons outside his/her support group interact with him/her') in which the subject is not the person with ASD. Thus, it might be understandable that people providing support take specific measures to strengthen participation in the community, independently of (or without considering) children's gender. Actually, there are another two items in which males scored higher than females but not significantly, which leads us to interpret that this is true since both males and females participate equally "in activities in their community with persons outside their support group" and "in social activities outside the place where they receive services or support". However, this highlights that, despite taking specific measures for them to participate in community social activities, females enjoy lower social inclusion and community participation than males as is highlighted in the other items. It may be possible that support and activities oriented to improve the social inclusion of people with ASD are biased for the male phenotype (Mademtzi, Singh, Shic, and Koenig, 2018). Against this, it is necessary to review these measures from a person-centered perspective in order to ensure that they are truly effective and adapted to the preferences of females and commensurate with their cognitive abilities.

The second hypothesis suggested that females would obtain lower scores in social inclusion even when variables such as level of ID, level of support needs, and age were controlled. Significant differences by gender were confirmed, although it must be noted that level of ID did not explain differences whereas level of supports needs and age explained an important percentage of social inclusion scores. In this way, differences did not rely on the level of intellectual functioning of the person, but on other moderator variables such as gender, age, and level of support needs (Gómez, Schalock and Verdugo 2019). In this 
regard, higher QOL and social inclusion-related outcomes are usually obtained by males and younger participants (Gómez, Peña, Arias, and Verdugo 2016; Morán, Gómez, and Alcedo 2018). Also, the availability or lack of support from others is another crucial variable to be considered as facilitator or barrier for participation (Obrusnikova and Cavalier, 2012). Likewise, visibility of disability may play a critical role in social inclusion outcomes given that, paradoxically, the less visible the disability is, the more support may be necessary (Tuersley-Dixon and Frederickson 2016). This may be the case for females with ASD, who may not only have more difficulties and challenges in social relations, but also experience more negative social attitudes and contextual obstacles to inclusion (Anaby et al. 2013; Askari et al. 2013).

In relation to the third hypothesis, none of the items presented DIF at statistical level. The itemlevel analysis proposed in this paper is considered an innovative and key contribution in respect to previous research by Arias et al. since it confirms that the conclusions are unbiased and, therefore, that the instrument evaluates both men and women in a uniform fashion, finding real differences in social inclusion personal outcomes by gender (i.e. differences are not a result of the measurement process or a biased instrument).

\section{Limitations}

Although we consider the results of this study are relevant for practitioners and key agents in the disability field to design better person-centered planning aimed to improve the social inclusion of youth and children with ASD and ID, some limitations must be pointed out. Firstly, conclusions are only applicable to those young people with ASD and a comorbid diagnosis of ID. Secondly, participants were not randomly selected, but results are based on a convenience sample so caution should be applied in terms of generalization of results.Also, the results of the DIF analysis should be regarded with caution given that, in order to reach adequate effect size and statistical power, it would be advisable to reach a sample size of 1,168 participants. At this respect, it must be noted that the sample is wide considering the difficulty of reaching and recruiting this population in a research study and that there is currently no consensus regarding effect size classification system for logistic regression DIF analyses (Scott et al. 2010). Thirdly, although the variable age was controlled and gender differences remained, the wide age range used in this study may also impact the generalizability of the results, so studying in depth narrower age ranges is highly recommended for future studies. Fourthly, we did not evaluate self-perception of social inclusion, but scores were based on a third-person's perspective. Proxy reports were used with the aim of overcoming the difficulties of obtaining valid responses from those with higher levels of ID and ASD symptoms who might 
struggle with language and communication. Future research should make efforts towards the development of methods to reliably gather perceptions and opinions of children with ASD, ID, and greater language difficulties. Lastly, the KidsLife-ASD scale show adequate evidences of reliability and validity based on content and internal structure of the scale (Gómez, Morán, Alcedo, Arias et al. 2018; Gómez, Morán, Alcedo, Verdugo et al. 2018; Morán et al. 2019) but more research is needed to provide evidences about concurrent validity and inter-rater reliability.

\section{Conclusion}

This study serves as additional evidence in a research field with little and inconsistent results. Our results support lower social inclusion scores for females with ASD, which are not always related to level of ID, support needs, or age. In this sense, it must be noted that social inclusion does not depend exclusively on the person with ASD, but also depends on the context, opportunities, and a gender perspective in the design, assessment, and implementation of individualized support, family strategies, professional practices, and organizational services aimed at enhancing social inclusion related personal outcomes. Given that gender differences may also depend on the context and cultural setting, transcultural studies would be necessary in order to be able to make comparisons among countries and check if gender differences are cross-cultural. 


\section{References}

Anaby, D., Hand, C., Bradley, L., DiRezze, B., Forhan, M., DiGiacomo, A., et al. (2013). The effect of the environment on participation of children and youth with disabilities: A scoping review. Disability and Rehabilitation, 35(19), 1589-1598. doi: 10.3109/09638288.2012.748840.

Andersson, G. W., Gillberg, C., \& Miniscalco, C. (2013). Pre-school children with suspected autism spectrum disorders: Do girls and boys have the same profiles? Research in Developmental Disabilities, 34(1), 413-422. doi:10.1016/j.ridd.2012.08.025.

Arias, V. B., Gómez, L. E., Morán, M. L., Alcedo, M. A., Monsalve, A., \& Fontanil, Y. (2018). Does quality of life differ for children with autism spectrum disorder and intellectual disability compared to peers without autism? Journal of Autism and Developmental Disorders, 48(1), 123-136. doi: 10.1007/s10803-017-3289-8.

Askari, S., Anaby, D., Bergthorson, M., Majnemer, A., Elsabbagh, M., \& Zwaigenbaum, L. (2015). Participation of children and youth with autism spectrum disorder: A scoping review. Journal of Autism and Developmental Disorders, 2, 103-114. doi:10.1007/s40489-014-0040-7.

Attwood, T. (2007). The complete guide to Asperger's syndrome. London: Jessica Kingsley Publishers.

Backer van Ommeren, T., Koot, H. M., Scheeren, A. M., \& Begeer, S. (2017). Sex differences in the reciprocal behaviour of children with autism. Autism, 21(6), 795-803. doi:10.1177/1362361316669622.

Baird, G., Douglas, H. R., \& Murphy, M. S. (2011). Recognising and diagnosing autism in children and young people: Summary of NICE guidance. BMJ, 21, 343. doi: 10.1136/bmj.d6360.

Baird, G., Simonoff, E., Pickles, A., Chandler, S., Loucas, T., Meldrum, D., et al. (2006). Prevalence of disorders of the autism spectrum in a population cohort of children in South Thames: The Special Needs and Autism Project (SNAP). Lancet, 368(9531), 210-215. doi:10.1016/S01406736(06)69041-7.

Banach, R., Thompson, A., Szatmari, P., Goldberg, J., Tuff, L., Zwaigenbaum, L., et al. (2009). Brief Report: Relationship between non-verbal IQ and gender in autism. Journal of Autism and Developmental Disorders, 39(1), 188-9. doi: 10.1007/s10803-008-0612-4. 
Begara, O., Gómez, L. E., \& Alcedo, M. A. (2019). Do young people with Asperger syndrome or intellectual disability use social media and are they cyberbullied or cyberbullies in the same way as their peers? Psicothema, 31(1), 30-37. doi: 10.7334/psicothema2018.243.

Begeer, S., Mandell, D., Wijnker-Holmes, B., Venderbosch, S., Rem, D., Stekelenburg, F., et al. (2013). Sex differences in the timing of identification among children and adults with autism spectrum disorders. Journal of Autism and Developmental Disorders, 43, 1151-1156. doi:10.1007/s10803-012-1656-z.

Billstedt, E., Gillberg, I. C., \& Gillberg, C. (2007). Autism in adults: Symptom patterns and early childhood predictors. Use of the DISCO in a community sample followed from childhood. Journal of Child Psychology and Psychiatry and Allied Disciplines, 48(11), 1102-1110. doi: 10.1111/j.1469-7610.2007.01774.x.

Cliff, N. (1993). Dominance statistics: Ordinal analyses to answer ordinal questions. Psychological Bulletin, 114, 494-509.doi: 10.1037/0033-2909.114.3.494.

Cohen, J. (1988). Statistical Power Analysis for the Behavioral Sciences. New York, NY: Routledge Academic.

Dean, M., Harwood, R., \& Kasari, C. (2017). The art of camouflage: Gender differences in the social behaviors of girls and boys with autism spectrum disorder. Autism, 21(6), 643-645. doi: 10.1007/s10803-013-1985-6.

Dworzynski, K., Ronald, A., Bolton, P., \& Happe, F. (2012). How different are girls and boys above and below the diagnostic threshold for autism spectrum disorders? Journal of the American Academy of Childhood Adolescent Psychiatry, 51(8), 788-797. doi: 0.1016/j.jaac.2012.05.018.

Fombonne, E. (2003). Epidemiological surveys of autism and other pervasive developmental disorders: An update. Journal of Autism and Developmental Disorders, 33(4), 365-382. doi: 10.1023/A:1025054610557.

Fombonne, E. (2005). The changing epidemiology of autism. Journal of Applied Research in Intellectual Disabilities, 18(4), 281-294. doi: 10.1111/j.1468-3148.2005.00266.x. 
Fombonne, E. (2009). Epidemiology of pervasive developmental disorders. Pediatric Research, 65(6), 591-598. doi: 10.1203/PDR.0b013e31819e7203.

Giarelli, E., Wiggins, L. D., Rice, C. E., Levy, S. E., Kirby, R. S., Pinto-Martin, J., et al. (2010). Sex differences in the evaluation and diagnosis of autism spectrum disorders among children. Disability and Health Journal, 3(2), 107-116. doi: 10.1016/j.dhjo.2009.07.001.

Goldman, S. (2013). Opinion: Sex, gender and the diagnosis of autism-A biosocial view of the male preponderance. Research in Autism Spectrum Disorders, 7(6), 675-679. doi: 10.1016/j.rasd.2013.02.006.

Gómez, L. E., Morán, M. L, Alcedo, M. A., Arias, V. B., \& Verdugo, M. A. (2018). Adapting the KidsLife Scale for use with autism and intellectual disability. Manuscript submitted for publication.

Gómez, L. E., Morán, L., Alcedo, M. A., Verdugo, M. A., Arias, V. B., Fontanil, Y., et al. (2018). Escala KidsLife-TEA: Evaluación de la calidad de vida de niños y adolescentes con autismo y discapacidad intelectual [KidsLife-ASD: quality of life assessment for children and adolescents with autism and intellectual disabilities]. Salamanca: INICO.

Gómez, L. E., Peña, E., Arias, B., \& Verdugo, M.A. (2016). Impact of individual and organizational variables on quality of life. Social Indicators Research, 125(2), 649-664. doi: 10.1007/s11205014-0857-6.

Gómez, L. E., Schalock, R. L., \& Verdugo, M. A. (2019). The Role of Logic Models and Moderator and Mediator Variables in Implementing and Evaluating IDD-Related Policies and Practices. Manuscript submitted for publication.

Gómez, L. E., Verdugo, M. A., \& Arias, B. (2010). Calidad de vida individual: Avances en su conceptualización y retos emergentes en el ámbito de la discapacidad [Individual quality of life: advances in its conceptualization and emerging challenges in the field of disability]. Behavioral Psychology/Psicología Conductual, 18, 453-472.

Gómez, J., Hidalgo, M. D., \& Zumbo, B. D. (2013). Effectiveness of combining statistical tests and effect sizes when using logistic discriminant function regression to detect differential item 
functioning for polytomous items. Educational and Psychological Measurement, 73(5), 875897. doi: $10.1177 / 0013164413492419$.

Gould, J., \& Ashton-Smith, J. (2011). Missed diagnosis or misdiagnosis? Girls and women on the autism spectrum. Good Autism Practice, 12(1), 34-41.

Gray, K. M., \& Tonge, B. J. (2005). Screening for autism in infants and preschool children with developmental delay. Australian and New Zealand Journal of Psychiatry, 39(5), 378-386. doi: 10.1080/j.1440-1614.2005.01585.x.

Halladay, A. K., Bishop, S., Constantino, J. N., Daniels, A. M., Koenig, K., Palmer, K., et al. (2015). Sex and gender differences in autism spectrum disorder: Summarizing evidence gaps and identifying emerging areas of priority. Molecular Autism, 6, 36-41.doi:10.1186/s13229-0150019-y.

Hartley, S. L., \& Sikora, D. M. (2009). Sex differences in autism spectrum disorder: An examination of developmental functioning, autistic symptoms, and coexisting behavior problems in toddlers. Journal of Autism and Developmental Disorders, 39(12), 1715-1722. doi:10.1007/s10803-009.

Hattier, M. A., Matson, J. L., Tureck, K., \& Horovitz, M. (2011). The effects of gender and age on repetitive and/or restricted behaviors and interests in adults with autism spectrum disorders and intellectual disability. Research in Developmental Disabilities: A Multidisciplinary Journal, 32(6), 2346-2351. doi: 10.1016/j.ridd.2011.07.028.

Hidalgo, M. D., Gómez J., \& Padilla J. L. (2005). Logistic regression: Analytic strategies in differential item functioning detection. Psicothema, 17, 509-515.

Holtmann, M., Bolte, S., \& Poustka, F. (2007). Autism spectrum disorders: Sex differences in autistic behaviour domains and coexisting psychopathology. Developmental Medicine and Child Neurology, 49(5), 361-366. doi:10.1111/j.1469-8749.2007.00361.x.

Honda, H., Shimizu, Y., \& Rutter, M. (2005). No effect of MMR withdrawal on the incidence of autism: A total population study. Journal of Child Psychology and Psychiatry, 46(6), 572-579. doi: 10.1111/j.1469-7610.2005.01425.x. 
Hull, L., Petrides, K. V., Allison, C., Smith, P., Baron-Cohen, S., Lai, M.C., et al. (2017). "Putting on my best normal”: Social camouflaging in adults with autism spectrum conditions. Journal of Autism and Developmental Disorders, 47(8), 2519-253. doi: 10.1007/s10803-017-3166-5.

Kirkovski, M., Enticott, P. G., \& Fitzgerald, P. B. (2013). A review of the role of female gender in autism spectrum disorders. Journal of Autism and Developmental Disorders, 43, 2584-2603. doi: 10.1007/s10803-013-1811-1.

Kose, S., Erermis, S., Ozturk, O., Ozbaran, B., Demiral, N., Bildik, T., et al. (2013). Health related quality of life in children with autism spectrum disorders: The clinical and demographic related factors in Turkey. Research in Autism Spectrum Disorders, 7, 213-220. doi: 10.1007/s10803-0090921-2.

Kuhlthau, K., Orlich, F., Hall, T. A., Sikora, D., Kovacs, E. A., Delahaye, J., et al. (2010). Health-related quality of life in children with autism spectrum disorders: Results from the autism treatment network. Journal of Autism and Developmental Disorders, 40, 721-729. doi: 10.1007/s10803009-0921-2.

Kuo, M. H., Orsmond, G. I., Cohn, E., \& Coster, W. J. (2013). Friendship characteristics and activity patterns of adolescents with an autism spectrum disorder. Autism, 17, 481-555. doi: $10.1177 / 1362361311416380$.

Kreiser, N. L., \& White, S. W. (2014). ASD in females: Are we overstating the gender difference in diagnosis? Clinical Child and Family Psychology Review, 17(1), 67-84. doi: 10.1007/s10567013-0148-9.

Lai, M.C., Lombardo, M.V., Ruigrok, A. N. V., Chakrabarti, B., Auyeung, B., Szatmari, P., et al. (2017). Quantifying and exploring camouflaging in men and women with autism. Autism, 21(6), 690702. doi: $10.1177 / 1362361316671012$.

Loomes, R., Hull, L., \& Mandy, W. P. L. (2017). What Is the Male-to-Female Ratio in Autism Spectrum Disorder? A Systematic Review and Meta-Analysis. Journal of the American Academy of Child \& Adolescent Psychiatry, 56(6), 466 - 474. doi: 10.1016/j.jaac.2017.03.013. 
Lugnegard, T., Hallerback, M. U., \& Gillberg, C. (2011). Psychiatric comorbidity in young adults with a clinical diagnosis of Asperger syndrome. Research in Developmental Disabilities, 32(5), 19101917. doi: 10.1016/j.ridd.2011.03.025

Mandy, W., Chilvers, R., Chowdhury, U., Salter, G., Seigal, A., \& Skuse, D. (2012). Sex differences in autism spectrum disorder: evidence from a large sample of children and adolescents. Journal of Autism and Developmental Disorders, 42(7), 1304-1313. doi:10.1007/s10803-011-1356-0.

May, T., Cornish, K., \& Rinehart, N. J. (2012). Gender profiles of behavioral attention in children with autism spectrum disorder. Journal of Attention Disorders, 20(7), 627-635. doi:10.1177/1087054712455502.

Mayes, S. D., \& Calhoun, S. L. (2011). Impact of IQ, age, SES, gender, and race on autistic symptoms. Research in Autism Spectrum Disorders, 5(2), 749-757. doi: 10.1016/j.rasd.2010.09.002.

Mademtzi, M., Singh, P., Shic, F., \& Koenig, K. (2018). Challenges of females with autism: A parental perspective. Journal of Autism and Developmental Disorders, 48(4), 1301-1310. doi:10.1007/s10803-017-3341-8.

Morán, L., Gómez, L. E., \& Alcedo, M. A. (2018). Segundo Premio de Investigación AMPANS 2018. Hacia una mejor calidad de vida en jóvenes con discapacidad intelectual y autismo: Prioridades para la intervención y variables relevantes. [Second Award in Research AMPANS 2018: Towards a better quality of life of youth with intellectual disabilities and autism: Priorities for intervention and relevant variables]. Available at http://www.ampans.cat/es/publicaciones-es/premio-de-investigacion.

Morán, L., Gómez, L. E., \& Alcedo, M.A. (in press). Inclusión social y autodeterminación: los retos en la calidad de vida de los jóvenes con autismo y discapacidad intellectual [Social inclusion and self-determination: the challenges in the quality of life of youth with autism and intellectual disability]. Siglo Cero.

Moses, L. E. (1952). Nonparametrical statistics for psychological research. Psychological Bulletin, 49(2), $122-143$. 
Obrusnikova I., \& Cavalier A. (2011). Perceived barriers and facilitators of participation in after-school physical activity by children with autism spectrum disorders. Journal of Developmental and Physical Disabilities, 23, 195-211.doi: 10.1007/s10882-010-9215-z.

Øien, R. A., Hart, L., Schjølberg, S., Wall, C. A., Kim, E. S., Nordahl-Hansen, A., et al. (2017). Parentendorsed sex differences in toddlers with and without ASD: Utilizing the M-CHAT. Journal of Autism and Developmental Disorders, 47, 126-134. doi: 10.1007/s10803-016-2945-8.

Øien, R. A., Schjølberg, S., Volkmar, F. R., Shic, F., Cicchetti, D. V., Nordahl-Hansen, A., et al. (2018). Clinical features of children with autism who passed 18-month screening. Pediatrics, 141(6), e20173596. doi: 10.1542/peds.2017-3596.

Park, S., Cho, S., Cho, I., Kim, B., Kim, J., Shin, M., et al. (2012). Sex differences in children with autism spectrum disorders compared with their unaffected siblings and typically developing children. Research in Autism Spectrum Disorders, 6, 861-870. doi: 10.1016/j.rasd.2011.11.006.

Reinhardt, V. P., Wetherby, A. M., Schatschneider, C., \& Lord, C. (2015). Examination of sex differences in a large sample of young children with autism spectrum disorder and typical development. Journal of Autism and Developmental Disorders, 45(3), 697-706. doi: 10.1007/s10803-0142223-6.

Rivet, T. T., \& Matson, J. L. (2011). Gender differences in core symptomatology in autism spectrum disorders across the lifespan. Journal of Developmental and Physical Disabilities, 23, 399420. doi: 10.1007/s10882-011-9235-3

Rubenstein, E., Wiggins, L. D., \& Lee, L. (2015). A review of the differences in developmental, psychiatric, and medical endophenotypes between males and females with autism spectrum disorder. Journal of Developmental and Physical Disabilities, 27(1), 119-139. doi: 10.1007/s10882-014-9397-x.

Russell, G., Steer, C., \& Golding, J. (2011). Social and demographic factors that influence the diagnosis of autistic spectrum disorders. Social Psychiatry and Psychiatric Epidemiology, 46(12), 12831293. doi: 10.1007/s00127-010-0294-z

Schalock, R. L., \& Verdugo, M. A. (2002). Quality of life for human service practitioners. Washington, DC: American Association on Mental Retardation. 
Schalock, R. L., Verdugo, M. A., \& Gomez, L. E. (2011). Evidence-based practices in the field of intellectual and developmental disabilities: An international consensus approach. Evaluation and Program Planning, 34(3), 273-82. doi: 10.1016/j.evalprogplan.2010.10.004.

Scott, N. W., Fayers, P. M., Aaronson, N. K., Bottomley, A., de Graeff, A., Groenvold, M., et al. (2010). Differential item functioning (DIF) analyses of health-related quality of life instruments using logistic regression. Health and quality of life outcomes, 8, 81. doi:10.1186/1477-7525-8-81

Sedgewick, F., Hill, V., Yates, R., Pickering, L., \& Pellicano, E. (2016). Gender differences in the social motivation and friendship experiences of autistic and non-autistic adolescents. Journal of Autism and Developmental Disorders, 46(4), 1297-1306. doi: 10.1007/s10803-015-2669-1.

Shields, N., Synnot, A., \& Kearns, C. (2015). The extent, context and experience of participation in outof-school activities among children with disability. Research in Developmental Disabilities, 47, 165-174. doi: 10.1016/j.ridd.2015.09.007.

Siklos, S., \& Kerns, K. A. (2007). Assessing the diagnostic experiences of a small sample of parents of children with autism spectrum disorders. Research in Developmental Disabilities, 28(1), 9-22. doi: 10.1016/j.ridd.2005.09.003.

Sung, C., Sánchez, J., Kuo, H., Wang, C., \& Leahy, M. J. (2015). Gender differences in vocational rehabilitation service predictors of successful competitive employment for transition-aged individuals with autism. Journal of Autism and Developmental Disorders, 45(10), 3204-3218. doi:10.1007/s10803-015-2480-z.

Solomon, M., Miller, M., Taylor, S. L., Hinshaw, S. P., \& Carter, C. S. (2012). Autism symptoms and internalizing psychopathology in girls and boys with autism spectrum disorders. Journal of Autism and Developmental Disorders, 42(1), 48-59. doi: 10.1007/s10803-011-1215-z.

Symes, W., \& Humphrey, N. (2010). Peer-group indicators of social inclusion among pupils with autistic spectrum disorders (ASD) in mainstream secondary schools: A comparative study. School Psychology International, 31(5), 478-494. doi: 10.1177/0143034310382496.

Trigo, M. E., \& Martínez, R. J. (2016). Generalized ETA square for multiple comparisons on betweengroups designs. Psicothema, 28, 340-345. doi: 10.7334/psicothema2015.124. 
Tsai, L., \& Beisler, J. (1983). The development of sex differences in infantile autism. The British Journal of Psychiatry, 142(4), 373.

Tsai, L., Stewart, M. A., \& August, G. (1981). Implication of sex differences in the familial transmission of infantile autism. Journal of Autism and Developmental Disorders, 11(2), 165-173.

Tuersley-Dixon, L., \& Frederickson, N. (2016). Social inclusion of children with complex needs in mainstream: does visibility and severity of disability matter? International Journal of Developmental Disabilities, 62(2), 89-97. doi: 10.1179/2047387715Y.0000000011.

Van Wijngaarden-Cremers, P. J. M., van Eeten, E., Groen, W. B., Van Deurzen, P. A., Oosterling, I. J., \& Van der Gaag, R. J. (2014). Gender and age differences in the core triad of impairments in autism spectrum disorders: A systematic review and meta-analysis. Journal of Autism and Developmental Disorders, 44(3), 627-635. doi: 10.1007/s10803-013-1913-9.

Vine Foggo, R. S., \&Webster, A. A. (2017). Understanding the social experiences of adolescent females on the autism spectrum. Research in Autism Spectrum Disorders, 35, 74-85. doi: 10.1016/j.rasd.2016.11.006.

Volkmar, F. R., Cook, E. H., Pomeroy, J., Realmuto, G., \& Tanguay, P. (1999). Practice parameters for the assessment and treatment of children, adolescents, and adults with autism and other pervasive developmental disorders. Journal of the Academy of Child \& Adolescent Psychiatry, $38,32 \mathrm{~S}-54 \mathrm{~S}$

WHOQOL Group. (1998). The World Health Organization WHOQOL-BREF quality of life assessment. Psychological Medicine, 28, 551-558.

Zumbo, B. D. (1999). A handbook on the theory and methods of Differential Item Functioning (DIF): Logistic regression modeling as a unitary framework for binary and Likert-type (ordinal) item scores. Ottawa: Directorate of Human Resources Research and Evaluation, Department of National Defense. 